\title{
The Contribution of Neuromarketing to the Study of Consumer Behavior
}

\author{
Claudia Almeida Colaferro ${ }^{\dagger}$ \\ Universidade de São Paulo - USP \\ Edson Crescitelli ${ }^{\Omega}$ \\ Universidade de São Paulo - USP
}

\begin{abstract}
Understanding consumer behavior in a society marked by complexity is a challenging task. The aim of this article is to investigate the new information that can be obtained by means of neuromarketing and whether it helps clarify knowledge about consumers. We performed an exploratory study involving review of the literature and in-depth interviews with Brazilian and international specialists. Our conclusion is that neuromarketing - or the application of neuroscience in the marketing area - can shed light on consumers' reactions to marketing actions.
\end{abstract}

Keywords: Consumer behavior. Cognitive sciences. Neuromarketing. Neuroscience. Marketing research.

$\dot{t}$. MSc. From the School of Economics and Administration of the University of São Paulo ' Address: Rua Prof Guilherme Milward, E-mail: claudia@colaferro.com Telephone: (11) 999337873

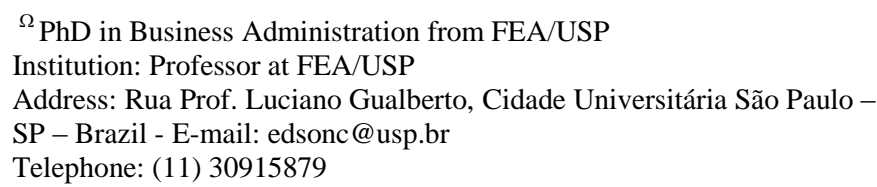




\section{INTRODUCTION}

nderstanding the behavior of consumers in a society marked by complexity

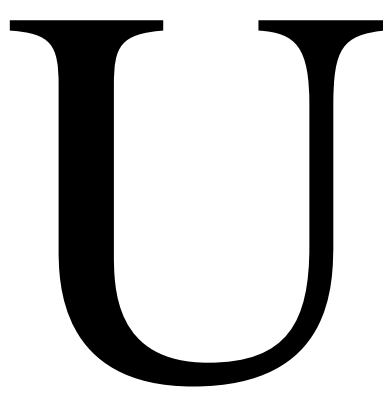
involves the study of many variables. In this scenario, as described by Lipovetsky (2008), by being ever more demanding, individuals become mired when faced with the present reality and dreams of the future. People live under pressure in the search to satisfy their needs and assure wellbeing. They aspire to participate in the world of consumption, leisure time and brands. Traditional references like sex, age and race no longer seem effective, and others gain relevance, such as differences of opinion, preferences, interests and the various forms of personal expression and behavior, mainly subconscious ones.

Changes in social dynamics, new technologies, new lifestyles and the presence of more aware consumers also challenge the hegemony of the mass media, in particular advertising, as a source of information. This triggers a crisis of credibility in this form of communication, since the receivers of messages are aware that advertisers are trying to convince them to buy, and consumers have a more critical and skeptical attitude, diminishing the persuasive power of this communication tool (CRESCITELLI, 2004).

Under these circumstances, with plurality of offers, where there is consumption of the ephemeral, in which everyone wants better consumption in the future, it is important to know not only the specific declared needs of individuals, but also their real motivations, conscious or unconscious. With this, the benefits offered by brands can go beyond value in relation to competitors and develop not only the intention of buying but also greater loyalty.

Therefore, study of behavior and its practices of investigation should be a continuing part of the flow of business rather than just an area to support marketing efforts. To succeed in this undertaking, marketers and researchers need to invest in techniques that can clarify information about consumers and better understand their behavior, through techniques such as ad hoc market studies, demographic and psychographic panels and exploratory projects like interviews using projective techniques, as described by Malhotra (2011).

However, there is a crisis of traditional investigation methods. These are seem as limited and relatively ineffective in understanding that a single individual can have distinct consumption styles, depending on the person's various roles in society, different moments during life phases and even within the daily routine. According to Malhotra (2011, p. 136), in direct interviews the respondent can, intentionally or not, misunderstand or misinterpret the 
researcher's queries, causing misleading results. To avoid this potential problem, projective techniques or non-traditional methods can increase the validity of the responses by uncovering the purpose. This occurs specifically in questions of a delicate personal nature or areas that are subject to social rules for exploration of motivations, beliefs and attitudes that operate at the subconscious level. Individuals nowadays are experiencing a continuous process of mutation.

Because of this complexity, the methods normally applied to understand human behavior offer results that are incomplete, immutable and restricted to explaining individuals' reactions and monitoring their alterations. What is sought with new methods is to improve the acuity of the inferences formed from the data, to enable formulation of better strategies to promote brands in the market. Besides the high cost of advertising and the emergence of new forms and media able to enhance the communication mix, it is fundamental to discuss the question of the behavioral changes that have been gaining force since the 1990s, as consumers have become increasingly aware of their rights (POON; PRENDERGAST, 2006).

Marketing studies in the applied social sciences area, as well as semiotics in communication science, psychology in the human sciences and neuroscience in the biological sciences, are examples of the various areas of knowledge that have been applied to understand how people think, act and interact with products and services, the similarities and differences in their selective processes, their desires and the factors that influence their consumption decisions.

This article investigates what new information can be gleaned by neuromarketing studies and if this information helps elucidate individuals' behavior, thus providing a better understanding of the factors that affect consumers' buying choices. For this purpose, we conducted an exploratory study involving review of the literature on consumer behavior and neuromarketing, to build a theoretical framework for a field investigation, consisting of indepth interviews with 13 Brazilian and foreign specialists, grouped into two categories: i) academics, namely researchers who use neuroscience as an instrument in scientific research; and ii) professional marketers, who use neuroscience as an instrument to investigate consumer behavior and provide consulting services in this field.

\section{THEORETICAL FRAMEWORK}

This section contains a review of the literature, identifying the different lines of thinking on each of the concepts relevant to the theme under analysis. We first provide a brief 
overview of research into consumers' behavior and decision processes and then highlight the contribution of neuroscience to the study of this behavior.

\subsection{CONSUMER BEHAVIOR}

The study of consumer behavior involves observation of consumers in their buying decision processes, from their initial search to the moment of purchase, as well as their aftersale assessment of products and services, in the expectation of obtaining information to allow companies to formulate proposals that satisfy customers' needs and demands. For Schiffman \& Kanuk (2000), the study of consumer behavior is interdisciplinary, based on concepts and theories of human behavior developed by scientists in areas as wide-ranging as psychology, sociology, social psychology, cultural anthropology and economics.

The consumer decision model investigated by these authors unites psychological, social and cultural concepts in an easily understood working structure. This model has three series of variables: the input variables or external variables, whether or not from the marketing environment; the process variables or those that are influenced by consumers' psychology; and the output variables or the previous experiences with the product. This process is depicted in Figure 1.

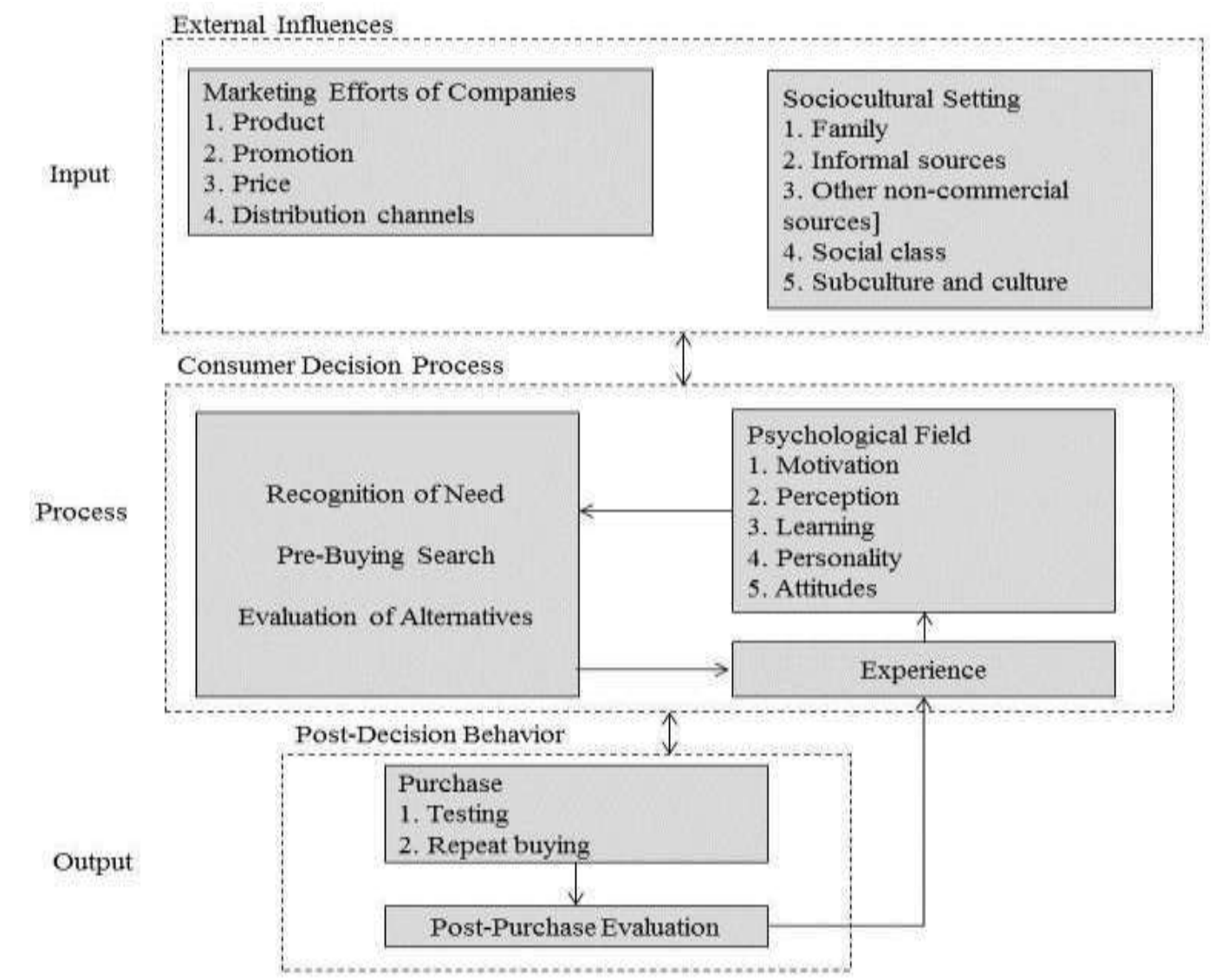

Figure 1 - Simple Model to Analyze Consumer Decisions

Source: Schiffman \& Kanuk (1997, p. 400) 
According to Robertson et al. (1984), consumers' behavior is stochastic, i.e., only probabilities of certain actions can be determined. In an updated proposal, Salomon (2002) demonstrated the use of different disciplines to research questions on the specific behavior in using magazines (Table 1):

\begin{tabular}{|c|c|}
\hline Focus of the discipline & Research questions about use of magazines \\
\hline $\begin{array}{l}\text { Experimental Psychology: The role of products } \\
\text { in the processes of perception, learning and } \\
\text { memory. } \\
\text { Clinical Psychology: The role of products in } \\
\text { psychological adjustment. } \\
\text { Microeconomics/Human Ecology: The role of } \\
\text { products in the distribution of individual or } \\
\text { household resources. } \\
\text { Social Psychology: The role of products in the } \\
\text { behavior of individuals as members of social } \\
\text { groups. } \\
\text { Sociology: The role of products in social } \\
\text { institutions and group relations. } \\
\text { Macroeconomics: The role of products in the } \\
\text { relations of consumers with the market. } \\
\text { Semiotics/Literary Criticism: The role of } \\
\text { products in the verbal and visual communication } \\
\text { of meaning. } \\
\text { Demography: The role of products in the } \\
\text { measurable characteristics of a population. } \\
\text { History: The role of products in social changes } \\
\text { over time. } \\
\text { Cultural Anthropology: The role of product in } \\
\text { the beliefs and practices of a society. }\end{array}$ & $\begin{array}{l}\text { How specific aspects, such as design, are } \\
\text { recognized and interpreted; what parts are most } \\
\text { likely to be read. } \\
\text { How they affect the physical image of readers (do } \\
\text { images of thin women generate a sensation of } \\
\text { obesity in others?). } \\
\text { Factors that influence the amount of money spent } \\
\text { on magazines. } \\
\text { How advertisements affect readers' attitudes about } \\
\text { the products presented; how peers influence a } \\
\text { person's reading decisions. } \\
\text { The pattern by which preferences for a magazine } \\
\text { spread in a social group. } \\
\text { Effects of the price of fashion magazines and } \\
\text { spending on the items advertised during } \\
\text { unemployment. } \\
\text { How the underlying messages conveyed by models } \\
\text { and advertisements in a magazine are interpreted. } \\
\text { Effects of age, income, marital status of a } \\
\text { magazine's readers. } \\
\text { Ways that cultural representations of "femininity" } \\
\text { in magazines change with time. } \\
\text { Ways that fashion and models in a magazine affect } \\
\text { readers' definitions of what masculine and } \\
\text { feminine roles are. }\end{array}$ \\
\hline
\end{tabular}

Table 1 - Utilization of Different Disciplines to Study Consumer Behavior

Source: Adapted from Solomon (2002, p. 41).

To evaluate the contribution of each technique to the understanding of consumer behavior, one can reflect on what phase of the behavior model of Schiffman \& Kanuk (1997) fits best:

- Focus group - declaratory research - phase of input and experience regarding the presence of a prototype in the group's analysis of alternatives.

- Preference questionnaire - phase of input and experience regarding the presence of a prototype in the respondents' analysis of alternatives.

- Simulation -output phase.

- Market testing - output phase. 
According to Ariely \& Berns (2010), marketing professionals in their search to provide the best product offers to customers can guide the product development process from design to presentation of the proposal, according to the perceived preferences of future users, to facilitate these users' selection process. This is done by means of information on what is valued by prospective customers in the process of seeking a product or service. In the effort to obtain information for better development of proposals, marketing practitioners can use a range of market research techniques, from focus groups and surveys with individuals to market tests. Depending on the target of investigation - type of consumer responses, phase of the marketing process, quantity of resources available — different marketing techniques can be used, each with its own advantages and limitations, as summarized in Table 2:

\begin{tabular}{|c|c|c|c|c|}
\hline & Focus groups & $\begin{array}{l}\text { Preference } \\
\text { questionnaires }\end{array}$ & $\begin{array}{l}\text { Simulated choice } \\
\text { methods }\end{array}$ & Market tests \\
\hline What is measured & $\begin{array}{l}\text { Open-ended } \\
\text { answers, body } \\
\text { language and } \\
\text { behavior, not } \\
\text { suitable for } \\
\text { statistical analysis. }\end{array}$ & $\begin{array}{l}\text { Importance } \\
\text { weighting for } \\
\text { various product } \\
\text { attributes. }\end{array}$ & $\begin{array}{l}\text { Choices among } \\
\text { products. }\end{array}$ & $\begin{array}{l}\text { Decision to buy } \\
\text { and choice among } \\
\text { products. }\end{array}$ \\
\hline $\begin{array}{l}\text { Type of response } \\
\text { process }\end{array}$ & $\begin{array}{l}\text { Speculative, } \\
\text { except when used } \\
\text { to assess } \\
\text { prototypes. }\end{array}$ & $\begin{array}{l}\text { The respondents } \\
\text { need to ponder } \\
\text { their decisions } \\
\text { through } \\
\text { introspection, and } \\
\text { then map these } \\
\text { thoughts on the } \\
\text { response scale. }\end{array}$ & $\begin{array}{l}\text { A hypothetical } \\
\text { choice, just like a } \\
\text { buying choice, but } \\
\text { without incurring } \\
\text { an expense. }\end{array}$ & $\begin{array}{l}\text { An effective } \\
\text { choice, with } \\
\text { customers who } \\
\text { spend money and } \\
\text { thus make real } \\
\text { choices. }\end{array}$ \\
\hline $\begin{array}{l}\text { Typical use in } \\
\text { new products }\end{array}$ & $\begin{array}{l}\text { At the start, to } \\
\text { help the design } \\
\text { and test the } \\
\text { prospective form } \\
\text { of use. }\end{array}$ & $\begin{array}{l}\text { In the design } \\
\text { phase, when the } \\
\text { choice is } \\
\text { important. }\end{array}$ & $\begin{array}{l}\text { In the design } \\
\text { phase when the } \\
\text { choice is } \\
\text { important. Can be } \\
\text { used as a } \\
\text { forecasting tool. }\end{array}$ & $\begin{array}{l}\text { At the end of the } \\
\text { process of } \\
\text { forecasting sales } \\
\text { and measuring the } \\
\text { response to other } \\
\text { marketing } \\
\text { elements, such as } \\
\text { price. }\end{array}$ \\
\hline $\begin{array}{l}\text { Cost and } \\
\text { competitive risk }\end{array}$ & $\begin{array}{l}\text { Low cost, risk } \\
\text { comes only from } \\
\text { misuses of data by } \\
\text { the seller. }\end{array}$ & $\begin{array}{l}\text { Moderate cost and } \\
\text { some risk of } \\
\text { alerting } \\
\text { competitors. }\end{array}$ & $\begin{array}{l}\text { Moderate cost } \\
\text { (higher if using } \\
\text { prototypes instead } \\
\text { of descriptions) } \\
\text { and some risk of } \\
\text { alerting } \\
\text { competitors. }\end{array}$ & $\begin{array}{l}\text { High cost and } \\
\text { high risk of } \\
\text { alerting } \\
\text { competitors, plus } \\
\text { the risk of this } \\
\text { product being } \\
\text { reverse engineered } \\
\text { before launch. }\end{array}$ \\
\hline $\begin{array}{l}\text { Technical skill } \\
\text { necessary }\end{array}$ & $\begin{array}{l}\text { Skill in } \\
\text { moderating group } \\
\text { discussions and } \\
\text { ethnographic } \\
\text { skills of the } \\
\text { observers and } \\
\text { analysts. }\end{array}$ & $\begin{array}{l}\text { Design of } \\
\text { questionnaire and } \\
\text { statistical analysis } \\
\text { of responses. }\end{array}$ & $\begin{array}{l}\text { Experimental } \\
\text { design and } \\
\text { statistical analysis, } \\
\text { including } \\
\text { modeling. }\end{array}$ & $\begin{array}{l}\text { Highly specialized } \\
\text { in market testing } \\
\text { (observation, } \\
\text { collection and } \\
\text { analysis of data) } \\
\text { and prediction } \\
\text { tools. Highly } \\
\text { specialized. }\end{array}$ \\
\hline
\end{tabular}




\begin{tabular}{|l|l|l|l|l|}
\hline Marketing phase & $\begin{array}{l}\text { For insight in the } \\
\text { formulation of } \\
\text { concept / product } \\
\text { /communication. }\end{array}$ & $\begin{array}{l}\text { Choice of options } \\
\text { among concept / } \\
\text { product / } \\
\text { communication. }\end{array}$ & $\begin{array}{l}\text { Choice among } \\
\text { final product } \\
\text { options. Pre- } \\
\text { launch phase. }\end{array}$ & $\begin{array}{l}\text { Post-launch } \\
\text { testing in the } \\
\text { existing market } \\
\text { and pre-launch } \\
\text { testing for } \\
\text { expansion into } \\
\text { other markets. }\end{array}$ \\
\hline
\end{tabular}

Table 2 - Comparison of Various Marketing Techniques

Source: Adapted from Ariely \& Berns (2010, p. 285).

Empirical studies of consumer behavior have used ideas from a many fields for support - anthropology, sociology, psychology, and more recently neuroscience - to better understand shoppers' preferences and behaviors in response to the stimuli offered to buy products. The stages of the buying decision process, in which consumers employ diverse mental processes to assess alternatives and make their choices, have been analyzed extensively from a cognitive perspective. According to Aschcraft (2002), cognition is the mental process or faculty of knowing, including aspects such as awareness, perception, reasoning and judgment.

\subsection{NEUROMARKETING}

The intention of this comparison is to evaluate the other techniques that can contribute to understanding of consumers' decision-making behavior, specifically in the field of psychology. In this respect, neuromarketing brings to bear a broader range of knowledge, aggregating to behavioral information the hidden motivations in the unconscious mind that guide individuals in their process of choosing. Hence, the aim is to formulate offers with greater value to customers, by applying methods from neuroscience and its diagnostic tools.

The term neuromarketing, according to Fisher et al. (2010), was first used in 2002 in a press release from a company based in Atlanta called BrightHouse, which announced the creation of a business unit using functional nuclear magnetic resonance imaging (fMRI) for marketing studies. This development attracted criticisms involving Emery University, because the company used its facilities, imaging studies and at least one of its psychiatry professors for these studies. But before this event, research into the reaction of consumers to television ads, measured by electroencephalography, had been used by corporations, and a patent application had been filed (published in August 2000) by two Harvard researchers, Gerald Zaltman and Stephen Kosslyn, called “Neuroimaging as a marketing tool”. In October 2004, The New York Times published a controversial article entitled "If you have a buy button in your brain, what pushes it?" in which the journalist Sandra Blakeslee described the novelties of neuromarketing and cast doubt on the imaging techniques used in marketing research. 
As stated by Lindstrom (2008), consumers simply cannot express what they really think consciously. The reactions and emotions are found in the brain for only a brief time and cannot be translated into descriptive responses to questionnaires, meaning that traditional investigations used for brand building are of doubtful utility. According to Castells (2009), the construction of a person's reality, such as reaction to internal and external events, happens with their processing according to individual patterns. The majority of this processing is unconscious and the reality is neither objective nor subjective, but rather the fruit of the construction of images that mix what is happening in the physical world (inside and outside the individual) with the material from past experiences accumulated in the mind during neural correspondences in time, among the characteristics of events and the catalog of responses available in the brain.

Recently, researchers have proposed different definitions of neuromarketing. More specifically: i) Lee et al. (2007) defined neuromarketing as an academic area instead of an application of neuroimaging techniques to sell products; and ii) Hubber \& Kenning (2008) described neuromarketing as a business activity rather than an academic area, denominated consumer neuroscience. For them, neuromarketing is only an application of the insights gained from this science in the field of management practices.

In the current literature, studies related to neuromarketing combine various noninvasive scientific imaging methods that measure the level of emotional attraction or repulsion that consumers experience when stimulated by a brand's marketing campaign. In this respect, mention can be made of Batista et al. (2008), in the area of visual perception of stimuli, who analyzed how test subjects react to complex scenes. They found that this reaction, involving attention and memory, goes beyond the focus of the evaluation to include distracting stimuli in the observer's environment. To assess the test subjects' perception and probable interferences, they used electrophysiological signals, such as those captured by electroencephalograms, and other devices like eye trackers to capture where the eye focuses attention on computer screen images. They also employed traditional questionnaires with scales to elicit reactions to scenes reproduced in the laboratory, and performed field research of the "real" situations in which the scene occurs. Another example is MacClure et al. (2004), who used consumer products to study concepts such as sensory processing, choice and evaluation of gains and losses. Specifically, they used fMRI to study the differences in reactions to Coca-Cola and Pepsi, to obtain insight into cultural symbols, not to propose development of new designs. Mention can also be made of Astolfi et al. (2008), who used 
EEG to measure the electrical activation of the regions of the brain stimulated by television ads. The results indicated that those best recalled several days afterward had activated distinct brain regions from those that had been forgotten, suggesting the need for further investigation of areas linked to memorization to shed more light on buying behavior.

One method used is steady state topography (SST), an advanced version of electroencephalography that has the advantage of also measuring the instantaneous reactions of the brain. The fMRI technique, which uses a scanner that can identify very small areas that were stimulated, is the most sophisticated device available in the market. The typical pattern of the studies carried out by market research firms is to use imaging instruments from neuroscience complemented by traditional qualitative surveys and measurements of body reactions, or biometrics, be they electrical, chemical and/or mechanical, such as eye-tracking, measurement of skin reactions (temperature, muscular contraction or electrical conductivity) and even facial responses to products and their stimuli. According to Jain et al. (2002), biometry is the science that identifies individuals based on their physiological or behavioral traits, with the fundamental properties of universality, uniqueness, permanence, measurement and circumvention.

A variety of technologies exist that provide different measures of brain functioning. According to Ariely \& Berns (2010), these are:

- Functional MRI (fMRI): This technique uses a magnetic resonance scanner to measure the level of blood-oxygen level dependency (BOLD). Changes in BOLD are generally correlated with synaptic activity, and this apparatus measures very small regions, but not quickly (resolution of 1-10 mm and time of 1-10 seconds).

- Electroencephalography (EEG): The EEG electrodes are applied to the scalp with the use of a gel to enhance conductivity, and alterations in the electrical field in the brain region just below are captured. EEG has fast time resolution (milliseconds) and can thus detect fleeting neuron events.

- Magnetoencephalography (MEG): A more expensive relative of EEG, MEG measures changes in the magnetic fields induced by neuron activity. It has the same advantage of high time resolution, and since the magnetic field is less distorted by the skull than is the electrical field, it allows better spatial resolution than EEG. Like EEG, MEG is more sensitive to signals from the cortical surface (mainly the brain folds). 
- Transcranial magnetic stimulation (TMS): An iron core, often in the shape of a torus (donut), wrapped with electrical wires, creates a magnetic field strong enough to induce electrical currents in the underlying neurons in the brain.

The majority of published studies have applied fMRI or EEG with the aim of identifying correlations between the stimulus and the area of the brain activated, to shed more light on behavior. However, there is a lack of recommended protocols, such as the ideal number of participants, to obtain valid and reproducible results. As mentioned by Spiers \& Maguire (2006), although studies involving analysis of advertisements are starting to offer important information, the fact that using fMRI requires the test subject to remain passive can mean the data are not truly representative of what happens in real life, since many daily reactions are influenced by the settings where people live, work and shop. Therefore, authors unanimously recommend further studies. According to Lee et al. (2007), the majority of the social sciences have not yet adopted neuroimaging as a standard research tool. Neuroeconomics started with the use of neuroimaging, but researchers in the field of marketing in general have been slow to realize the benefits of imaging studies, even though both fields of study share common concerns related to processes of decision and exchange. This is based on the fact that the scope of marketing research in business schools is essential to understand, explain and predict certain relevant behavior, be it of individuals, groups or organizations. Hence, the use of the knowledge generated from academic studies to meet commercial interests represents a natural barrier to the development of neuromarketing, since the use of brain images invades the privacy of individuals. However, even in academic circles there are concerns about the ability of neurological methods to assess the panoply of relevant variables in marketing theories, as mentioned by Spiers \& Maguire (2006). Although admitting that progress has been made in the use of fMRI, they expressed concern over its laboratory application and ability to be proven in real life.

An article published in July 2010 in the Harvard Review of Psychiatry raised more worries about the simplistic conclusions of some neuromarketing studies, as well as the lack of transparency in a field whose academic foundations are hard to define or identify. In September that year, the Advertising Research Foundation (ARF), the main American selfregulatory entity of marketing research, announced a project called NeuroStandards Initiatives, with the participation of eight research firms that use neuroscience for market investigations. These firms submitted their methods to a review with the objective of formulating rules on the use of techniques and to create guidelines, or common procedures, 
for validation of the results obtained and to prevent problems or disputes over ethical questions. The standards created were the first set of scientific principles for application of EEG and other brain mapping techniques to marketing research.

\section{FIELD RESEARCH}

With the aim of elucidating the different contributions of behavioral research, its main characteristics, difficulties and gains in its use for marketing, we complemented the literature review with a field study to elicit viewpoints of experts on the contribution of neuromarketing to the understanding of consumer behavior. This study is exploratory and qualitative in nature, relying on descriptive variables aimed to explore the field of neuroscience and its possible contribution to the investigation of the consumer behavior. For this purpose, we conducted in-depth interviews with experts from two distinct groups: i) academics who in some form study neuroscience and its application in the area of human behavior; and ii) practitioners, some of them also academics, who use neuroscience studies commercially as a tool to investigate consumer behavior.

The specific research objectives were the following: i) to assess whether neuromarketing can be a new area of collaboration to understand consumers; ii) to learn the undeclared information on consumers that can be captured from the brain to corroborate the process of understanding their behavior; iii) to discover which techniques are used and recommended; iv) to find out the main marketing questions to be investigated; v) to obtain opinions on the contributions and difficulties of neuromarketing; and vi) to define possible future developments.

\subsection{METHOD ADOPTED}

The field study had an exploratory approach in which we used semi-structured and semi-open in-depth interviews following a basic script. The interviews were conducted in person or by telephone, similar to an informal conversation without determined responses. They were recorded and transcribed for later interpretation.

The interviews were conducted between July and September 2011, and because of geographical considerations, most were by telephone or Skype. In one case it was by exchange of email messages, in the form of an open questionnaire. All the interviews followed the same general script: i) nome, position, place of work, education; ii) opinion of the evolution of behavioral research and the methods used in the respondent's experience; iii) knowledge of neuroscience and its application to marketing (neuromarketing) and the way to obtain the desired knowledge; iv) a definition of neuromarketing by the respondent, types of 
investigative applications used in neuromarketing, recommendation on types of studies, and possibilities for use; v) description of the possible contributions to the study of behavior, the barriers and difficulties that need to be overcome and the advantages and disadvantages; vi) existence of concerns regarding ethical questions; vii) exploration of other methods that can be combined to enrich knowledge and the diversity of areas of wisdom: the future of the area, its next steps and the needs that must be met, ways of staying abreast of the latest developments and sources of information; and; viii) any added comments.

All told, we interviewed 13 experts in the two categories described above, selected by convenience: Group 1 (Dr. Gerald Zaltman - professor of business administration emeritus Harvard Business School; Dr. Carl D. Marci - professor of neuroscience at MIT and president of the consultancy Innerscope Research, Boston, USA; Dr. Michael Brammer - professor of neuroscience at the University of London and president of the consultancy Neurosense Institute, England; Dr. M. Vinicius C. Baldo - professor of neuroscience at the Institute of Biomedical Sciences of the University of São Paulo; Dr. Luiz E. Ribeiro do Valle - professor of neuroscience at the Institute of Biomedical Sciences of the University of São Paulo; Dr. Fabio Babiloni - professor at La Sapienza University, Rome); and Group 2 (Dr. David Lewis - professor of neuroscience in the Experimental Psychology Department of the University of Sussex and founder/president of the consultancy The Mindlab International; Ms. Silvia Quintanilha - vice-president of Milward Brown International Brasil; Dr. Billy E. M. Nascimento - neuroscientist and founder/executive director of Forebrain Institute, a neuromarketing consultancy in Brazil; Mr. Karl Rosenberg - M.Sc. in social and experimental psychology and senior vice-president of MSW/LAB Biometrics Insights; Dr. Philip Rosenberg - PhD in psychology and information design and vice-president of One to One Insight; Mr. Pedro Camargo - a lawyer and part owner of the company Neurolabs; and Mr. Carlos Augusto Costa - an electronic engineer and coordinator of the Neuromarketing Laboratory of Getulio Vargas Foundation).

We applied content analysis to the responses, based on Bardin (2007). She defines this analysis as involving a set of systematic procedures applied to describe the content of messages that includes indicators, quantitative or not, to enable drawing inferences from knowledge related to conditions of production/reception and their variables. What is sought is correspondence between the semantic or linguistic structures and the psychological or sociological structures of the respondents. The treatment of the data permits making inferences and interpretations of the transcribed responses, broken down into segments that 
are categorized and codified according to the purposes of the research. After this, the frequency of the appearances is verified, according to the themes chosen for analysis, identified according to the case in each interview. Finally, the technique involves thematic analysis and examination of the frequency of the themes extracted from the set of interviews.

\subsection{RESULTS AND ANALYSIS}

The themes, which followed a script, were chosen and categorized as follows: Involvement with consumer behavior; Reasons for studying consumer behavior; Involvement with neuroscience and more familiar techniques; Definition of neuromarketing and possible measures; Possibilities for application in marketing phases; Techniques utilized; Advantages and limitations; Concerns; Future; and Sources of information. All the themes are the fruit of the declarations on the respondents, with their frequency being analyzed based on Bardin (2007).

In relation to the measurements, they were carried out by simple counting, thus analyzing the interpretations and positions of the 13 interviewees as a whole. Table 3 summarizes the conclusions. It contains the 10 categories and the leading belief among the respondents. We next make some comments on each category.

The first category refers to the involvement of the respondents with the study of consumer behavior, with the intention of capturing the richness of experience on the theme. This involvement can be classified into three categories, according to the professional background of the respondent: academic training, professional development and deepening or just curiosity.

The second category refers to the reasons for studying behavior, in light of the previous category. The respondents all expressed a real interest in the theme, be it as an additional source of information, to complement the basic training or for professional development.

The third category refers to the involvement by the panel with neuroscience and their interest in seeking responses to understand consumer behavior in some manner, whether from

biometric (non-academic) measurements or electrical brain responses or location of stimulated areas (mainly the responses to images, the technique most explored by academics).

The fourth category involves the definition of neuromarketing in the opinion of the respondents. The concept preferred by the academics (unanimously) was that neuromarketing is an application of neuroscience to marketing investigations. Three of the practitioners also 
cited this as the preferred definition, so that eight of the participants agreed in this respect, that neuromarketing is an application of neuroscience, not a new science unto itself.

The fifth category refers to the possibilities of applying neuromarketing in the different phases or sub-products of marketing. These areas elected by the panel are listed in Table 9. The predominant contribution mentioned was the possibility of obtaining information on the response to stimuli from communication or advertising, cited by eight respondents, mainly composed of practitioners. This was followed by the possibility of measuring the emotion generated by stimuli, declared by seven of the thirteen respondents, with predominance of academics.

The sixth category elucidates the techniques used in neuromarketing evaluations. For the most part this involves the use of biometric measurements, mainly by eye tracking and measurement of electrical signals from the brain, recorded by EEG. Studies with brain imaging were used mainly by the academics, due to limitations of investment and also the form of application when studying consumers.

The seventh category refers to the advantages and limitations of neuromarketing studies. The advantages most often mentioned were: increased understanding of the mind and subconscious with reduced uncertainties (mentioned by $70 \%$ of the respondents overall and $44 \%$ of the academics); and use to complement other data collection methods, mentioned by $44 \%$ of the respondents, divided equally between academics and practitioners. On the limitations side of the coin, 50\% (three of six) of the academics mentioned the lack of accepted standard protocols. This group also mentioned the multiplicity of methods of application to investigate behavioral reactions and the difficulty of combining data obtained from different sources and by different means to reach a diagnosis.

The eighth category focused on the preoccupations expressed by the respondents. Nine of the thirteen declared their concern regarding the lack of commonly accepted patterns to serve as the foundation for studies, causing the presence of biases from false interpretations about the data collected through "black box" methods (methods not open to peer review). The academics, besides that worry, also expressed concern over alarmism or lack of clarification of the study data to the population, which can cause unfounded beliefs and fears. The practitioners, in turn, mentioned in second place the possibility of unrepresentative population samples. 
The ninth category refers to future developments in the field. Regarding the next step of neuromarketing, six of the participants stated this would be through combining methods from different areas of knowledge. This was mentioned by four of the six academics and two of the seven practitioners. The second development most often mentioned by the academics involved portability - techniques to obtain data on the response to stimuli while test subjects are engaged in their normal daily activities rather than in a laboratory setting. The practitioners, on the other hand, more often mentioned combining different techniques to collect data, to improve their interpretation and understanding.

Finally, in the tenth category, the panel analyzed the sources of information. Both groups stated they sought information mainly by reading. However, the sources of this reading differed, with the academics mainly consulting articles published in scientific journals and practitioners seeking information in more general publications, from authors from various areas, and even from the Internet.

\begin{tabular}{|l|l|}
\hline Neuromarketing: Summary of 10 Categories & \\
\hline 1. Involvement with consumer behavior & $\begin{array}{l}\text { Deeper understanding of consumer behavior was } \\
\text { the leading reason mentioned. }\end{array}$ \\
\hline 2. Reasons for studying consumer behavior & $\begin{array}{l}\text { Better understanding of consumer behavior was } \\
\text { the leading response. }\end{array}$ \\
\hline $\begin{array}{l}\text { 3. Involvement with neuroscience and more } \\
\text { familiar techniques }\end{array}$ & $\begin{array}{l}\text { Deeper understanding, using biometry } \\
\text { (practitioners) or images (academics) }\end{array}$ \\
\hline $\begin{array}{l}\text { 4. Definition of neuromarketing and possible } \\
\text { measures }\end{array}$ & $\begin{array}{l}\text { An application of neuroscience to marketing to } \\
\text { measure the intensity of the response to stimuli. }\end{array}$ \\
\hline 5. Possibilities for application in marketing phases & $\begin{array}{l}\text { Analysis of communication, prototyping and } \\
\text { navigation by virtual stores or websites were the } \\
\text { most often mentioned. }\end{array}$ \\
\hline 6. Techniques utilized & $\begin{array}{l}\text { Biometry and electroencephalography are the most } \\
\text { used, with highlight on eye tracking. }\end{array}$ \\
\hline 7. Advantages and limitations & $\begin{array}{l}\text { Advantages: Reduction of uncertainties and } \\
\text { complementation of information are most often } \\
\text { mentioned. } \\
\text { Limitations: Measurements are still confined to the } \\
\text { laboratory and lack of published material on the } \\
\text { theme. }\end{array}$ \\
\hline 8. Concerns & $\begin{array}{l}\text { Misinterpretation of the results is the leading } \\
\text { worry, followed by manipulation of the results. }\end{array}$ \\
\hline 9. Future & $\begin{array}{l}\text { Search for a greater combination of scientific areas } \\
\text { to improve studies is expected. }\end{array}$ \\
\hline 10. Sources of information & Academic sources and non-academic authors. \\
\hline
\end{tabular}

Table 3: Summary of the 10 Categories from the Content Analysis about Neuromarketing

(Explicit form from what was declared by the respondents, analyzed according to Bardin, 2007)

Source: Prepared by the authors.

According to the panel's responses, neuromarketing - or the application of neuroscience to marketing - can provide added insights into the reactions to the stimuli from brands. Studies of subconscious responses are increasingly common in the market. International and national market research firms already regularly offer studies applying biometry or 
electroencephalography as techniques to measure consumer responses to products. Many of the academics on the panel have published articles on biometry and EEG, as well as imaging studies to locate stimulated areas of the brain. These are not generally offered to the market by consultancies because of the high cost of the instruments and also the limitation on use in large groups of consumers or in real-life situations. According to the majority view of the panel, what is offered to date is measurement of the intensities of reactions and their polarization as a way to measure the reactions to marketing stimuli. These can be ideas, prototypes, messages and/or navigation in virtual stores or real websites.

Despite the intention to understand and identify the correlation with the generating event, this is still not widely exploited commercially, and in the academic world there is a continuing search for the origin of reactions. The search for protocols and further studies is encouraged by those involved in studies of neuroscience, and the pace of development is fast, but there are still few publications and exchanges between the various sciences or between companies on the best practices or the ways to combine results.

There is collaborative project seeking collective validations about the theory of neuromarketing being conducted by the Advertising Research Foundation (ARF). The aim of this initiative is to establish common procedures and best practices. It is being guided by a multidisciplinary team formed of representatives of companies and research institutes along with scientists from universities, all of whom are engaged in studying consumer behavior by applying neuroscience in the United States. Establishment and validation of standard procedures is seen as useful, but with a certain degree of skepticism, since the group leading the effort does not include representatives of some important research firms, and its findings so far have only been exchanged among the collaborators.

The final conclusions of this empirical study are summarized in Table 4

\begin{tabular}{|c|l|}
\hline NEUROMARKETING & \multicolumn{1}{|c|}{ FIELD RESEARCH } \\
\hline What is measured & $\begin{array}{l}\text { An application of neuroscience to marketing to } \\
\text { measure the intensity of the responses to stimuli. }\end{array}$ \\
\hline Type of response process & $\begin{array}{l}\text { Quantitative data on intensity of responses to } \\
\text { stimuli from cerebral reactions and biometric } \\
\text { measurements. The most frequent are electrical } \\
\text { measurements from the scalp and visual responses } \\
\text { by tracking eye movements. }\end{array}$ \\
\hline Typical use & $\begin{array}{l}\text { The majority defined analysis of communication, } \\
\text { prototyping and navigation, whether by virtual } \\
\text { stores or websites. }\end{array}$ \\
\hline Costs and risks & $\begin{array}{l}\text { The use of biometry and EEG does not involve } \\
\text { high costs. Limitations: measurements still } \\
\text { confined to the laboratory and lack of material } \\
\text { published on the theme, besides misinterpretation }\end{array}$ \\
\hline
\end{tabular}




\begin{tabular}{|c|l|}
\hline & $\begin{array}{l}\text { of the results and manipulation of them as a } \\
\text { consequence. }\end{array}$ \\
\hline Technical skill necessary & $\begin{array}{l}\text { Highly specialized and composed of various } \\
\text { scientific specializations. Need for more methods } \\
\text { involving combination of measurements. }\end{array}$ \\
\hline Marketing phase & $\begin{array}{l}\text { The majority stated analysis of communication, } \\
\text { prototyping and navigation, whether by virtual } \\
\text { stores or websites. }\end{array}$ \\
\hline Phase of the decision process & $\begin{array}{l}\text { Measurement of the intensity of responses to ideas } \\
\text { and prototypes in the input phase and also in the } \\
\text { decision process, measuring the response to stimuli } \\
\text { provoked by the brand. Most frequent citations: } \\
\text { advertising, navigation experience and point of } \\
\text { sale. }\end{array}$ \\
\hline
\end{tabular}

Table 4 - Summary of the Contributions of Neuromarketing

Source: Prepared by the authors.

Our intention was to study the theme of neuromarketing and the undeclared information on consumers that can be captured from the brain to shed more light on their buying behavior. Table 4 shows the areas of contribution and recommendations for ways of using neuroscience techniques to study consumer behavior, as well as the phases of the marketing effort to for most effective application of these techniques, so as to add knowledge in collaboration with other methods.

\section{FINAL CONSIDERATIONS}

The objective of this study was to evaluate whether neuromarketing can be considered a new area of collaboration for understanding consumer behavior, focusing on its capacity to obtain undeclared information that can be captured from the brain to help understand the process of making buying decisions.

The in-depth interviews with specialists from various areas contributed to understanding the theme of neuromarketing, by addressing different angles of the theme and the use of neuroscience to complement traditional marketing techniques, as proposed by Ariely \& Berns (2010). Examples of these traditional methods are the use of focus groups and questionnaires, which provide information declared by individuals in a test situation. But the responses often do not reflect what will happen in reality at the moment of purchase because these techniques do not reveal undeclared influences of marketing stimuli. The use of investigations of the mind can minimize errors and adjust the marketing mix for a possible launch/simulation or market tests.

The results of this study also indicate the need for a better understanding of the decision-making process, analyzed here based on Schiffman \& Kanuk (1997). The intention is to improve understanding of this process through an input-process-output model, as illustrated in Figure 1, offering the possibility of additional information on the procedural/psychological 
aspects of individuals, obtained through techniques to measure undeclared reactions to stimuli and their polarity by application of neuroscience measurement techniques.

In the vision of the academics and practitioners, the application of neuroscience to marketing investigations can add valuable knowledge to traditional marketing studies, mainly by measuring the responses to stimuli from communication and advertising.

The use of neuroscience enables learning the responses of individuals through their positive and negative emotions, which can be achieved, according to $70 \%$ of the panel (found in the seventh category of investigation), by increasing the understanding of the subconscious mind, to reduce the uncertainties of the results of declared responses in consumer focus groups and surveys.

The advantage mentioned second most by the panel was that neuroscience can bring gains by complementing other information gathering methods (cited by $44 \%$ of the respondents, evenly divided between academics and practitioners). Therefore, it can be considered a new source that can provide a novel perspective to the study of consumer behavior. The respondents also indicated the need for continuing investigation of the theme, since it involves areas that only recently have begun to be explored by science, i.e., the search for basic knowledge of the functioning of the brain and the possible correlations with human behavior.

This study also revealed a potential disadvantage of neuroscience, namely the lack of generally accepted protocols. This generates problems for studies in the areas. This aspect was mentioned by the academic group, as reported in the seventh category of Table 3 .

The respondents also mentioned other important limitations, such as the multiplicity of methods to investigate behavioral reactions and the difficulty of combining data in different forms from distinct collection methods to formulate a single diagnosis. The establishment of protocols for application of these studies can enable better comparison of the results and also of the data collected, increasing the knowledge of these discoveries and evidencing the restrictions and uncertainties. An important initiative in this respect is that of the ARF, with the presence of academics and practitioners, in an effort to establish protocols and best practices for sharing and use in future studies. However, initiatives like this are just starting.

The majority of the panel, as revealed in the ninth category of the study, expressed the belief that combining methods from different areas of knowledge is the best way to develop neuromarketing. This response was given by four of the six academics, who also indicated the 
need for further development of assessment techniques that can be used outside the laboratory setting, allowing more precise findings by learning the reactions to real-world stimuli.

It is important to mention some limitations of this study. The first is its exploratory character, in only relying on a small number of academics and practitioners, not necessarily representative of the opinions of the academic and business communities as a whole. As mentioned, the group was chosen by convenience, selected from an investigation of the relevant subjects related to the theme and recently published articles, both in scholarly journals and the business press.

Another limitation is related to the lack of consolidated theories and academic articles on the subject, given its novelty. In many cases what we could find were data from combinations between methods without protocols. Besides this, knowledge of the subject, when available, comes from a wide range of fields, such as psychology, medicine, mathematics, statistics and psychiatry. This situation generates a level of complexity that is difficult to overcome. Along with the theoretical limitation, there is a shortage of protocols and collective validations on the theory of neuromarketing, as already mentioned.

As a suggestion for future research, it would of course be important to continue investigations of the theme - the relations between marketing stimuli and consumers' responses - not only to construct a more consistent theoretical framework, but also to apply it in different aspects of marketing, such as analysis of prototypes, communication, analysis of navigation of sites and also simulators of virtual environments.

Another suggestion for future investigation is research to validate EEG prototypes and also to develop portable biometric testing devices to analyze reactions in real settings. This would provide results nearer to what really happens in everyday life. The introduction of programs that can combine data from diverse sources of investigation would also be of great utility, possibly offering valuable contributions.

As a final consideration, neuromarketing - as mentioned in the studies summarized in the literature review and also explored in the interviews - adds knowledge on consumer behavior not permitted by traditional marketing study techniques. Its discoveries can be deepened with each new study, contributing to the evolution of marketing regarding knowledge of consumers. However, for this to occur, both academics and practitioners must respect the principles and protocols of scientific research. 


\section{REFERENCES}

ARF. Advertising Research Foundation. Neurostandards collaboration project. 2011. Disponível em: <http://www.thearf.org/assets/neurostandards-collaboration>. Acesso em: 30 ago. 2011.

ARIELY, D.; BERNS, G. S. Neuromarketing: the hope and hype of neuroimaging in business. Nature reviews / Neuroscience, v. 11, abr. 2010.

ASHCRAFT, M. H. Cognition. 3. ed. New Jersey: Prentice-Hall, 2002.

ASTOLFI, L. et al. Basis for brain responses to TV commercials: a high-resolution EEG study. IEEE Transactions on Neural Systems and Rehabilitation Engineering, v. 16, n. 6, 2008.

BARDIN, Laurence. Análise de conteúdo. 4. ed. Lisboa: Edições 70, 2007.

BATISTA, L. L. et al. Aspectos cognitivos da percepção da propaganda. Ciências \& Cognição, v. 13, 2008.

BLAKESLEE, S. If you have a "buy button" in your brain, what pushes it? The New York Times, October 19, 2004. Disponível em: <http://www.uky.edu/AS/PoliSci/Peffley/pdf/Blakeslee\%20NYT\%2004\%20_If\%20You\%20 Have\%20a\%20'Buy\%20Button'\%20in\%20Your\%20Brain,\%20What\%20Pushes\%20It.pdf>. Acesso em: 30 ago. 2011.

CASTELLS, M. Communication power. Oxford (UK): Oxford University Press, 2009.

CRESCITELLI, E. Crise de credibilidade da propaganda: considerações sobre seu impacto na eficácia da mensagem. Revista FACOM - Faculdade de Comunicação da FAAP, São Paulo, $2^{\circ}$ sem., 2004.

FISHER, C. E. et al. Defining neuromarketing: practices and professional challenges. Harvard Review Psychiatry Perspectives, 2010.

HUBERT, M.; KENNING, P. I. A current overview of consumer neuroscience. Journal of Consumer Behavior, n. 7, 2008.

JAIN, A. K. et al. Biometrics personal identification in networked society. Kluwer Academic Publishers: Massachussets, 2002

McCLURE, S. M. et al. Neural correlates of behavioral reference for culturally familiar drinks. Neuron, n. 44, 2004.

LEE, N. et al. What is neuromarketing? A discussion and agenda for future research.

International Journal of Psychophysiology, v. 63, 2007.

LINDSTROM, M. Buyology: truth and lies about why we buy. New York: Doubleday, 2008.

LIPOVETSKY, G. La sociedad de la decepción. Barcelona: Editorial Anagrama, 2008. 
MALHOTRA, N. K. Pesquisa de marketing: foco na decisão. 3. ed. São Paulo: Pearson Prentice Hall, 2011.

OLIVEIRA, E. C. Comportamento do consumidor processo de decisão de compra de livros pela internet. São Paulo: Universidade de São Paulo (USP), 2007.

POON, D. T. Y.; PRENDERGAST, G. A new framework for evaluating sponsorship opportunities. International Journal of Advertising, v. 25, n. 4, 2006.

ROBERTSON, T. S. et al. Consumer behavior. New York: Scott Foremann and Company, 1984.

SCHIFFMAN, L. G.; KANUK, L. L. Comportamento do consumidor. Rio de Janeiro: LTC - Livros Técnicos e Científicos Editora, 2000.

SPIERS, H. J.; MAGUIRE, E. A. Spontaneous mentalizing during an interactive real world task: an fMRI study. Neuropsychologia, v. 44, 2006.

SOLOMON, M. R. O comportamento do consumidor: comprando, possuindo e sendo. Porto Alegre: Bookman, 2002.

THORNTON, D. J. Brain culture: neuroscience and popular media. Rutgers University Press. New Brunswick: New Jersey, 2011 Disponível em:

<http://www.wired.com/wiredscience/2011/08/the-rhetoric-of-neuroscience/>. Acesso em: 30 ago 2011.

ZALTMAN, G.; STEPHEN, M. K. Neuroimaging as a marketing tool. US Patent 6,099,319. 8 ago. 2000. 